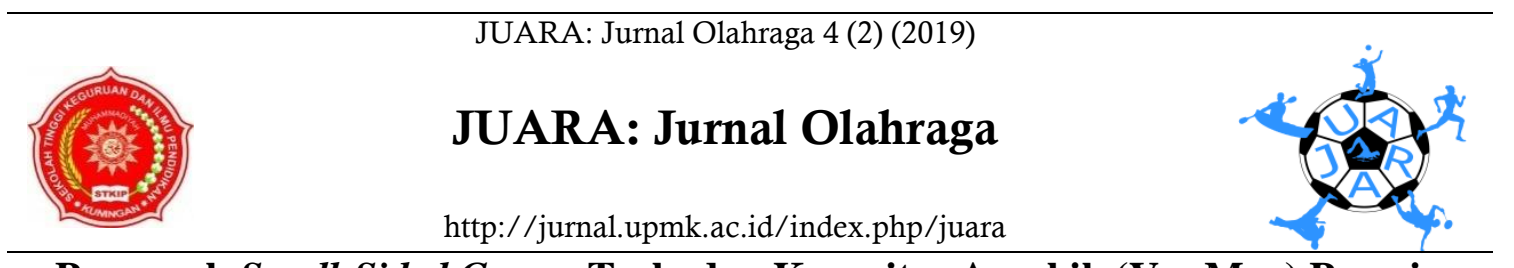

Pengaruh Small-Sided Games Terhadap Kapasitas Aerobik (Vo $o_{2}$ Max) Pemain Sepakbola

\title{
The Effect of Small Sided Games Toward Aerobic Capacity (Vo2 Max) Football Player
}

\author{
Oman Hadiana $^{1)}$, Didi Muhtarom ${ }^{2)}$ 'Dani Nurdiansyah ${ }^{3)}$ \\ 1,2,3 Department of Physical Education, Health and Recreation, STKIP Muhammadiyah \\ Kuningan, Jl. R.A. Moertasiah Soepomo No. 28 B, Kuningan, Kec. Kuningan, Kabupaten \\ Kuningan, Jawa Barat 45511, Indonesia \\ email: hadianaoman@upmk.ac.id ${ }^{1}$, karom@upmk.ac.id ${ }^{2}, \underline{\text { dani@upmk.ac.id }}^{3}$ \\ do) https://doi.org/10.33222/juara.v4i2.635
}

\begin{tabular}{l}
\hline Info Artikel \\
\hline Sejarah Artikel: \\
Diterima 1 Juli 2019 \\
Disetujui 30 Juli 2019 \\
Dipublikasikan 31 Juli 2019 \\
\hline Keywords: \\
Small-sided games, \\
VO ${ }_{2}$ max, intensitas, \\
sepakbola
\end{tabular}

\begin{abstract}
Abstrak
Sepakbola merupakan permainan yang dilakukan selama 90 menit waktu normal. Dalam memenuhi kebutuhan fisik pemain, perlu pemeliharaan dan peningkatan kapasitas aerobik (VO2max). penggunaan metode latihan small-sided games dalam sepakbola masa kini banyak digunakan dengan tujuan untuk meningkatkan kapasitas aerobik. Tujuan penelitian ini untuk menguji apakah penggunaan latihan small-sided games dapat meningkatkan kapasitas aerobik pemain sepakbola. Metode yang digunakan adalah eksperimen dengan the randomized pretest-posttest control group design. Sebanyak empat puluh dua pemain sepakbola Unit Kegiatan Mahasiswa (UKM) STKIP Muhammadiyah Kuningan dijadikan sebagai sampel penelitian. Teknik pengambilan yang digunakan adalah simple random sampling. Hasil penelitian menunjukkan bahwa kapasitas aerobik secara signifikan meningkat sebesar 6,62\% setelah diberi perlakuan berupa metode latihan small-sided games.
\end{abstract}

\begin{abstract}
Soccer is a game performed for 90 minutes of normal time. In meeting the physical needs of players, it is necessary to maintain and increase aerobic capacity (VO2max). the use of small-sided games in contemporary football is widely used to increase aerobic capacity. The purpose of this study is to examine whether the use of small-sided games can increase the aerobic capacity of soccer players. The method used was an experiment with the randomized pretest-posttest control group design. A total of forty-two soccer players STKIP Muhammadiyah Kuningan Student Activity Unit (UKM) were used as research samples. The retrieval technique used is simple random sampling. The results showed that aerobic capacity significantly increased by $6.62 \%$ after being treated in the form of small-sided games.
\end{abstract}


(C) 2019 Oman Hadiana, Didi Muhtarom, Dani Nurdiansyah Under the license CC BY-SA 4.0

\footnotetext{
$\bowtie$ Alamat korespondensi: Jl. R.A. Murtasiah Soepomo No. 28B

E-mail : : hadianaoman@upmk.ac.id

No Handphone : 0856-2025-609

PENDAHULUAN
}

Sepakbola merupakan permainan yang dilakukan selama 90 menit waktu normal, dan ditambah 30 menit waktu tambahan apabila skor masih imbang untuk kedua kesebelasan. Untuk memenuhi kebutuhan fisik pemain, diperlukan kondisi fisik yang prima salah satunya kapasitas aerobik (Vo2max) yang mencukupi kondisi fisik pemain bisa beradaptasi terhadap tuntutan waktu pertandingan tersebut. Smallsided-games merupakan metode latihan yang umum digunakan dalam pelatihan sepakbola.

Mengingat terbatasnya waktu yang tersedia untuk latihan kebugaran dalam sepakbola, keefektifan small-sided games sebagai stimulus pengkondisian perlu dioptimalkan untuk memungkinkan pemain bersaing di level tertinggi. Studi yang tersedia menunjukkan bahwa respons fisiologis (misalnya detak jantung, konsentrasi laktat darah dan peringkat aktivitas yang dirasakan), persyaratan keterampilan taktis dan teknis dapat dimodifikasi selama small-sided games dengan mengubah faktor-faktor seperti jumlah pemain, ukuran lapangan, aturan main, dan melatih dorongan semangat (Aguiar, et al., 2012).

Dalam olahraga prestasi telah didokumentasikan dengan baik bahwa manfaat maksimum dicapai ketika rangsangan pelatihan mirip dengan tuntutan kompetitif (Bompa, 1983). Small-sided games mengoptimalkan waktu pelatihan dengan memenuhi berbagai persyaratan kebugaran tanpa mengurangi kinerja keterampilan dan pengambilan keputusan.
ISSN 2655-1896 (online)

ISSN 2443-1117 (cetak)

Oleh karena itu, mereka digunakan secara luas untuk meningkatkan tingkat kebugaran fisik dan juga kinerja teknis dan taktis dalam berbagai kode sepakbola (Balsom, 1999; Aguiar, et al., 2012).

Intensitas latihan khusus sepak bola ini dengan bola dapat dipengaruhi atau dimanipulasi untuk memberikan respons fisik, teknis dan taktis yang berbeda oleh beberapa faktor, seperti, jumlah pemain yang terlibat, ukuran dan bentuk lapangan, durasi latihan dan waktu istirahat, aturan permainan, ketersediaan bola atau dengan cara mencetak poin (Bangsbo, 1994; Balsom, 2000; Hill-Haas, et al., 2009).

Beberapa dekade yang lalu metode latihan small-sided games ini banyak digunakan untuk mengembangkan aspek teknik dasar dan keterampilan bermain, sedangkan paradigma penggunaan metode latihan small-sided games masa kini banyak digunakan dengan tujuan untuk meningkatkan kapasitas aerobik (Balsom, 1999; Bangsbo, 2003; Drust, et al., 2000; Reilly, T., \& Gilbourne, 2003; Rampinini E, et al., 2007). Pembaharuan dengan penelitian terdahulu yaitu penelitian yang kami lakukan ini menerapkan metode latihan small-sided games bentuk interval dalam meningkatkan kapasitas aerobik (Vo2max) dengan memberikan treatment tiga tahap intensitas low - medium - hight.

Hasil temuan utama dari penelitian yang dilakukan oleh (Dellal et al., 2011) menyatakan bahwa dengan mengubah jumlah sentuhan pada bola yang diinstruksikan dalam small-sided games, pelatih dapat memanipulasi tuntutan fisik dan teknis dalam game tersebut. Penelitian yang kami lakukan untuk memanipulasi 
tuntutan dan tahapan intensitas dalam permainan yaitu dengan memberikan penguatan/dorongan verbal kepada seluruh pemain di setiap dimensi ukuran lapangan.

Latihan sepakbola menggunakan small-sided games menghasilkan respon detak jantung dalam ambang rangsang intensitas (Hoff, et al., 2002). Hal serupa diperkuat hasil penelitian sebelumnya oleh (Helgerud, et al., 2001) menemukan bahwa small-sided games efektif dalam meningkatkan kapasitas aerobik pemain sepakbola dengan menjalankan latihan interval 90-95\% dari denyut nadi maksimal. Hasil penelitian lain menunjukkan bahwa latihan yang dilakukan selama 12 minggu menggunakan interval aerobik dengan metode small-sided games efektif dalam meningkatkan kapasitas aerobik dan kondisi fisik selama pertandingan (Impellizzeri, F. et al., 2006).

Akhir ini semakin meningkatnya minat pemain dalam mengikuti latihan sepakbola, akan tetapi belum banyak penelitian yang menyelidiki secara sistematis dampak latihan small-sided games terhadap peningkatan kapasitas aerobik. Demikian pula, masih terbatasnya penelitian yang menilai reproduktivitas dan variabilitas antar partisipan dari respon fisiologis yang ditimbulkan oleh metode latihan ini (Rampinini E, et al., 2007).

Tujuan dari penelitian ini untuk menguji dampak dari penerapan metode latihan small-sided games terhadap kapasitas aerobik (Vo2max) pemain sepakbola.

\section{METODE PENELITIAN}

Jenis penelitian yang digunakan dalam penelitian adalah true eksperimen. Penelitian eksperimen merupakan salah satu metodologi penelitian paling kuat yang dapat digunakan para peneliti. Dari banyak jenis penelitian yang dapat digunakan, percobaan adalah cara terbaik untuk membangun hubungan sebab-akibat antar variabel. Desain yang digunakan adalah the randomized pretest-posttest control group design (Frankel et al., 2012). Adapun konstelasi desain penelitian sebagai berikut:

The Randomized Pretest-Posttest

Control Group Design

\begin{tabular}{lllll}
\hline Treatment group & $R$ & $O$ & $X$ & $O$ \\
\cline { 2 - 4 } Control group & $R$ & $O$ & $C$ & $O$ \\
\hline
\end{tabular}

Sebanyak empat puluh dua pemain sepakbola Unit Kegiatan Mahasiswa (UKM) STKIP Muhammadiyah Kuningan dijadikan sebagai sampel penelitian. Teknik pengambilan yang digunakan adalah simple random sampling (Sugiyono, 2013). Penelitian ini juga telah mendapat persetujuan resmi dari pembina dan lembaga independen. Tim sepak bola UKM STKIP Muhammadiyah Kuningan diberikan program latihan 2 jam tiap sesi latihan selama 12 minggu. Rangkaian latihan fisik dilakukan hanya dengan menggunakan small-sided games dengan beberapa variasi. Latihan dimainkan pada tiga area bermain yang berbeda ukurannya: lapangan berukuran sedang, lapangan besar $(20 \%$ lebih besar dari lapangan sedang), dan lapangan kecil $(20 \%$ lebih kecil dari lapangan berukuran sedang) (dapat dilihat pada tabel 1). 


\begin{tabular}{|c|c|c|c|}
\hline \multirow[b]{2}{*}{ Games } & \multicolumn{3}{|c|}{ Dimensions } \\
\hline & Small & Medium & Large \\
\hline Three-a-side & $12 \times 20 \mathrm{~m}$ & $15 \times 25 \mathrm{~m}$ & $18 \times 30 \mathrm{~m}$ \\
\hline Four-a-side & $16 \times 24 \mathrm{~m}$ & $20 \times 30 \mathrm{~m}$ & $24 \times 36 \mathrm{~m}$ \\
\hline Five-a-side & $20 \times 28 \mathrm{~m}$ & $25 \times 35 \mathrm{~m}$ & $30 \times 42 \mathrm{~m}$ \\
\hline Six-a-side & $24 \times 32 \mathrm{~m}$ & $30 \times 40 \mathrm{~m}$ & $36 \times 48 \mathrm{~m}$ \\
\hline
\end{tabular}

Selama penelitian, latihan interval dengan small-sided games terdiri dari tiga set dengan durasi 4 menit dan 3 menit pemulihan aktif antara set. Ini dilakukan dua kali seminggu (Senin dan Kamis) sebanyak 12 kali pertemuan.Setiap sesi latihan interval dilakukan pada awal sesi latihan khusus setelah pemanasan 20 menit yang terdiri dari lari intensitas rendah, samba (koordinasi), dan peregangan. Instrumen yang digunakan untuk mengukur kapasitas aerobik (Vo2max) menggunakan bleep test (Mackenzie, 2005).

Teknik analisis data penelitian dilakukan dengan bantuan softwere SPSS versi 21 (Gozali, 2013). Uji hipotesis menggunakan Paired Sample T-Test untuk mengetahui perbedaan rata-rata dua sampel berpasangan, dan Independent Sample TTest untuk mengetahui perbedaan rata-rata dua sampel yang tidak berpasangan.

\section{HASIL DAN PEMBAHASAN}

\section{Pengaruh Metode Latihan Small-Sided Game Terhadap Kapasitas Aerobik (Vo2max)}

Berdasarkan analisis statistika menggunakan SPSS versi 21 dapat diinterpretasikan sebagai berikut:

\begin{tabular}{|c|c|c|c|c|c|c|c|c|}
\hline \multicolumn{9}{|c|}{ Tabel 2. Paired Samples Test Kelompok Eksperimen } \\
\hline & \multicolumn{5}{|c|}{ Paired Differences } & \multirow[b]{3}{*}{$\mathrm{t}$} & \multirow[b]{3}{*}{$\mathrm{df}$} & \multirow{3}{*}{$\begin{array}{l}\text { Sig. }(2- \\
\text { tailed) }\end{array}$} \\
\hline & \multirow[b]{2}{*}{ Mean } & \multirow{2}{*}{$\begin{array}{c}\text { Std. } \\
\text { Deviation }\end{array}$} & \multirow{2}{*}{$\begin{array}{l}\text { Std. Error } \\
\text { Mean }\end{array}$} & \multicolumn{2}{|c|}{$\begin{array}{l}\text { 95\% Confidence } \\
\text { Interval of the } \\
\text { Difference }\end{array}$} & & & \\
\hline & & & & Lower & Upper & & & \\
\hline $\begin{array}{l}\text { Pair 1Pretest eksperimen } \\
\text { Posttest eksperimen }\end{array}$ & -3.095 & .301 & .066 & -3.232 & -2.958 & -47.156 & 20 & .000 \\
\hline
\end{tabular}

Dari hasil perhitungan analisis paired samples $t$-test mengenai perbedaan pengaruh antara hasil pretest dan posttest pada kelompok eksperimen (metode latihan small-sided games) terhadap kapasitas aerobik pemain sepakbola menunjukkan bahwa nilai Sig. (2-tailed) sebesar 0,000 < 0,05 . Berdasarkan analisis tersebut terdapat peningkatan signifikan kapasitas aerobik sebesar $6,42 \%$ setelah diberikan metode latihan small-sided games.

Temuan di lapangan menunjukkan bahwa kapasitas aerobik secara signifikan meningkat setelah diberi perlakuan berupa metode latihan small-sided games. Hasil penelitian ini juga diperkuat oleh (Rampinini E, et al., 2007), analisisnya menunjukkan bahwa detak jantung (intensitas) dan konsentrasi laktat darah lebih tinggi selama menggunakan smallsided games dalam latihan sepakbola. Intensitas latihan yang lebih tinggi yang diamati selama menggunakan small-sided games para pemain memiliki lebih banyak penguasaan bola. (Balsom, 1999) melaporkan peningkatan tiga kali lipat 
dalam jumlah penguasaan bola tiap pemain selama 20 menit. Karena berlari dengan bola membutuhkan pengeluaran energi yang lebih besar daripada berlari tanpa bola, ini bisa menjelaskan intensitas latihan yang lebih tinggi (Reilly, T., \& Ball, 1984). Sementara penelitian lain menyatakan bahwa pelatihan aerobik generik dan spesifik pada intensitas adekuat atau di atas 90\% dari denyut nadi maksimal diketahui meningkatkan kebugaran aerobik dan performa dalam bermain sepakbola (Helgerud, et al., 2001; Impellizzeri, F. et al., 2006).

Reproduksibilitas intensitas pada small-sided games sebanding baik dengan siklus ergometri dan treadmill yang berjalan di laboratorium. Oleh karena itu, smallsided games dapat digunakan secara andal untuk merangsang adaptasi fisiologis dan peningkatan kapasitas aerobik dalam permainan sepakbola seperti yang disarankan oleh studi pelatihan kami barubaru ini (Impellizzeri, F. et al., 2006).

\section{Pengaruh Metode Latihan Konvensional Terhadap Kapasitas Aerobik (Vo2max)}

Berdasarkan hasil analisis statistika menggunakan SPSS versi 21 dapat diinterpretasikan sebagai berikut:

Tabel 3. Paired Samples Test Kelompok Konvensional

\begin{tabular}{|c|c|c|c|c|c|c|c|c|c|}
\hline & \multicolumn{5}{|c|}{ Paired Differences } & \multirow[b]{3}{*}{$\mathrm{t}$} & \multirow[b]{3}{*}{ df } & \multirow{3}{*}{$\begin{array}{l}\text { Sig. }(2 \\
\text { tailed) }\end{array}$} \\
\hline & & \multirow[b]{2}{*}{ Mean } & \multirow{2}{*}{$\begin{array}{c}\text { Std. } \\
\text { Deviation }\end{array}$} & \multirow{2}{*}{$\begin{array}{l}\text { Std. Error } \\
\text { Mean }\end{array}$} & \multicolumn{2}{|c|}{$\begin{array}{l}\text { 95\% Confidence } \\
\text { Interval of the } \\
\text { Difference }\end{array}$} & & & \\
\hline & & & & & Lower & Upper & & & \\
\hline Pair 1 & $\begin{array}{l}\text { Pretest konvensional } \\
\text { Posttest konvensional }\end{array}$ & -2.571 & 1.028 & .224 & -3.039 & -2.103 & -11.461 & 20 & .000 \\
\hline
\end{tabular}

Dari perhitungan analisis paired samples $t$-test mengenai perbedaan pengaruh antara hasil pretest dan posttest pada kelompok kontrol (metode latihan konvensional) terhadap kapasitas aerobik pemain sepakbola menunjukkan bahwa nilai Sig. (2-tailed) sebesar $0,000<0,05$. Berdasarkan analisis tersebut terdapat peningkatan signifikan dari kemampuan awal kapasitas aerobik sebesar 5,58\% setelah diberikan metode latihan konvensional.

Temuan di lapangan menunjukkan bahwa kapasitas aerobik secara signifikan meningkat setelah diberi perlakuan metode latihan konvensional berupa lari kontinyu (countinous run). Latihan countinous run (lari terus menerus tanpa istirahat) berlangsung untuk waktu yang lama. lari terus menerus lebih dari 30 menit dengan tempo dibawah ambang rangsang anaerobik (annaerobic thresshold) akan menghasilkan adabtasi arobik dengan baik (Harsono, 2001). Hasil penelitian ini diperkuat oleh Alfian Yoga Wiratna, 2016 yang melakukan penelitian terhadap 30 responden siswa akademi salatiga training center. Berdasarkan analisa data hasil uji wilcoxon test didapatkan nilai $\alpha<0,05(\alpha=0,001)$ pada kelompok perlakuan yang berarti bahwa ada pengaruh pemberian countinous running terhadap peningkatan $\mathrm{VO}_{2}$ max pada pemain sepak bola. Sedangkan pada kelompok kontrol didapat hasil $\alpha=1,000$ yang artinya Ho di terima sehingga tidak terjadi perubahan pada kelompok kontrol. Dari keterangan diatas dapat di simpulkan bahwa countinous running dapat meningkatkan VO2max sebesar 3,5\%. Hal ini disebabkan karena adanya pemberian countinous 
running pada responden kelompok perlakuan yang sebelumnya belum pernah melakukan serta pemberian perlakuan dilakukan selama 12 kali pertemuan dengan frekuensi 3 kali dalam seminggu. Suatu pelatihan yang dilakukan berulang-ulang selama 4 minggu akan terpola pada sistem daya tahan kardiovaskuler yang menghasilakan efek adaptasi sehingga memberikan pengaruh terhadap peningkatan
VO2max para anak didik salatiga akademi training center.

\section{Pengaruh Perbedaan Metode Latihan Small-Sided Games dengan Metode Konvensional Terhadap Kapasitas Aerobik ( $\left.\mathrm{VO}_{2} \mathrm{max}\right)$}

Berdasarkan hasil analisis statistika menggunakan SPSS versi 21 dapat diinterpretasikan sebagai berikut:

Tabel 4. Independent Samples Test

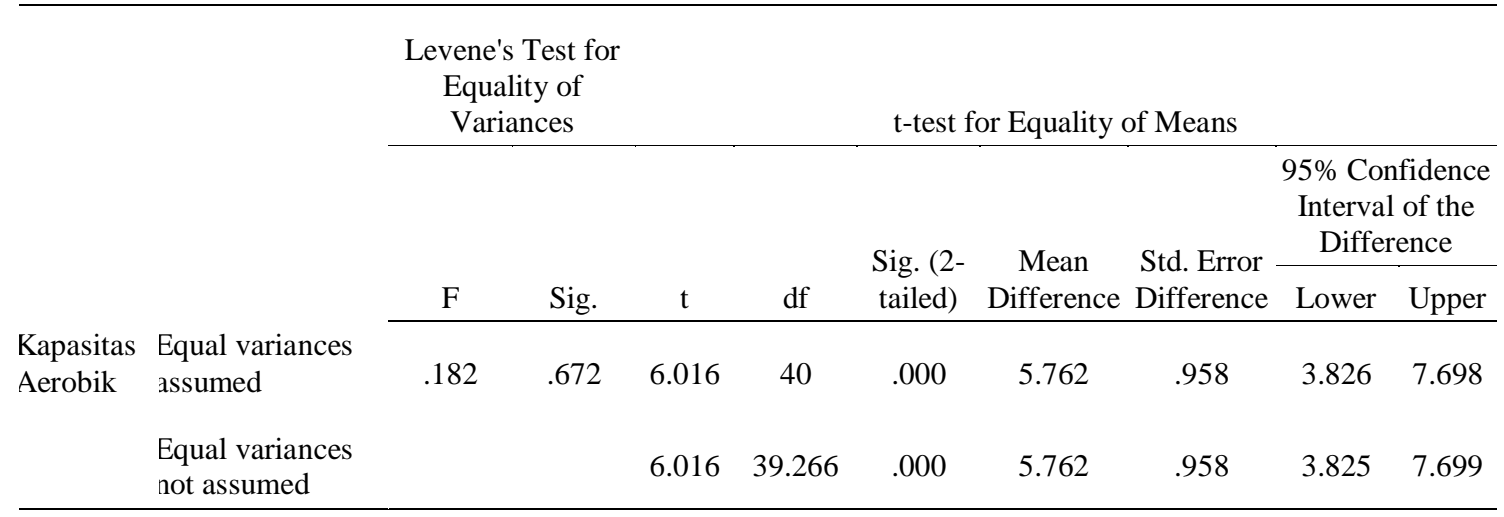

Dari data tabel di atas hasil perhitungan analisis independent samples $t$ test mengenai perbedaan pengaruh antara metode latihan small-sided games dengan metode latihan konvensional terhadap kapasitas aerobik $\left(\mathrm{VO}_{2} \max \right)$ menunjukkan bahwa nilai Sig. (2-tailed) sebesar 0,005 < 0,05 . Artinya terdapat perbedaan pengaruh hasil kapasitas aerobik menggunakan metode latihan small-sided games dengan metode latihan konvensional. Hal ini dapat dilihat pula peningkatan dari kemampuan awal kapasitas aerobik kelompok eksperimen yang menggunakan metode latihan small-sided games lebih tinggi sebesar $6,42 \%$ dari pada peningkatan dari kemampuan awal kelas kontrol yang menggunakan metode latihan konvensional (continuous run) sebesar 5,58\%.

Temuan penelitian diperkuat oleh (Dellal et al., 2011)menunjukkan bahwa modifikasi ukuran lapangan permainan dan jumlah pemain mempengaruhi kegiatan teknis, tuntutan fisik, dan respons fisiologis pemain sepak bola selama latihan menggunakan small-sided games. Modifikasi jumlah pemain dan keseimbangan lawan (Hill-Haas, et al., 2010) telah terbukti mengubah total jarak yang ditempuh, serta performa lari dan berlari yang berintensitas tinggi. Dalam kaitan dengan $\mathrm{O}_{2}$, olahdaya anaerobik berarti besar tuntutan akan $\mathrm{O}_{2}$, sedangkan olahdaya aerobik adalah besar pasokan $\mathrm{O}_{2}$. Oleh karena itu olahdaya aerobik hanya akan meningkat apabila olahdaya anaerobik meningkat, artinya untuk merangsang peningkatan kapasitas aerobik harus dilakukan dengan olahraga aerobik dengan intensitas anaerobik (intensitas) yang harus lebih besar daripada kapasitas aerobik yang dimiliki pada waktu itu. Jadi artinya lebih lanjut ialah bahwa untuk dapat meningkatkan kapasitas aerobik maka 
intensitas latihan harus overload $=$ super maksimal dan dalam durasi yang adekuat untuk olahraga aerobik (Giriwijoyo, 2013).

Sedangkan latihan menggunakan metode konvensional yaitu continuous run memberikan juga pengaruh yang terhadap peningkatan VO2max. (Harsono, 2001), "Ada tiga sistem latihan atau basic forms yang dapat menjamin peningkatan daya tahan kardiovaskular, yaitu sistem continuous training, playing with speed,interval training". Jika latihan continuous dilakukan dengan benar dan teratur perkembangan daya tahan akan meningkat, hal ini seperti yang dijelaskan oleh (Harsono, 2001),"Dengan berlatih (latihan kontinu) dengan intensitas 70\% sebanyak tiga sesi perminggu selama beberapa minggu, perkembangan daya tahan akan sangat terasa". Dari penjelasan tersebut dan sejalan dengan hasil penelitian yang diperoleh maka sistem latihan continuous memang dapat meningkatkan kapasitas $\mathrm{VO}_{2}$ max pemain sepakbola (Ray, 2018).

\section{SIMPULAN}

Berdasarkan hasil analisis dan pembahasan terkait dengan penerapan metode latihan small-sided games memberikan dampak yang signifikan terhadap kapasitas aerobik $\left(\mathrm{VO}_{2} \mathrm{max}\right)$ pemain sepakbola, karena small-sided games menyajikan metode latihan yang memberikan stimulus intensitas berada pada super maksimal. Latihan continuous run memberikan dampak terhadap kapasitas aerobik pemain sepakbola. Penerapan smallsided games dan latihan continuous run memiliki perbedaan terhadap peningkatan kapasitas aerobik pemain sepakbola, dimana metode latihan dengan menggunakan smallsided games memberikan dampak yang lebih signifikan.

Hasil penelitian ini berupa implementasi latihan small-sided games dapat dijadikan rujukan bagi para pelatih sepakbola dan ahli dalam bidang olahraga sebagai salah satu rancangan program latihan fisik dalam meningkatkan kapasitas aerobik pemain sepakbola.

\section{DAFTAR PUSTAKA}

Aguiar, M., Botelho, G., Lago, C., MaçAs, V., \& Sampaio, J. (2012). A review on the effects of soccer small-sided games. Journal of Human Kinetics, $33(1)$, 103-113. https://doi.org/10.2478/v10078-0120049-x

Balsom, P. (1999). Precision Football. Kempele, Finland: Polar Electro Oy.

Balsom P. (2000). Precision Football. Kempele: Polar Electro Oy.

Bangsbo, J. (1994). The physiology of soccer - with special reference to intense intermittent exercise. Acta Physiol Scan, 15, (Suppl. 619), 1-156.

Bangsbo, J. (2003). Physiology of Training. London: Routledge.

Dellal, A., Chamari, K., Lee Owen, A., Wong, D. P., Lago-Penas, C., \& HillHaas, S. (2011). Influence of technical instructions on the physiological and physical demands of small-sided soccer games. European Journal of Sport Science, 11(5), 341-346. https://doi.org/10.1080/17461391.2010 .521584

Drust, B., Reilly, T., \& Cable, N. T. (2000). Physiological responses to laboratorybased soccer specific intermittent and continuous exercise. Journal of Sports Sciences, 18, 885-892.

Giriwijoyo, S. (2013). Ilmu Faal Olahraga. Bandung.

Gozali, I. (2013). Aplikasi Analisis Multivariate degan Program IBM SPSS 21. Semarang: Badan Penerbit Universitas Diponogoro.

Harsono. (2001). Latihan Kondisi Fisik. Jakarta: CV. Irwan.

Helgerud, J., Engen, L. C., Wisloff, U., \& Hoff, J. (2001). Aerobic endurance training improves soccer performance. Medicine and Science in Sports and Exercise, 33, 1925 - 1931. 
Hill-Haas, S., Coutts, A. J., Dawson, B. T., \& Roswell, G. K. (2010). Time _motion characteristics and physiological responses of small-sided games in elite youth players: The influence of player number and rule changes. Journal of Strength and Conditioning Research, 24, 21492156.

Hill-Haas S. Dowson BT. Couts AJ. Rowsel GJ. (2009). Physiological responses and time-motion characteristics of various small-sided soccer games in youth players. J Sports Sci, 27 (1), 1-8.

Hoff, J., Wisloff, U., Engen, L. C., Kemi, O. J., \& Helgerud, J. (2002). Soccer specific aerobic endurance training. British Journal of Sports Medicine, 36, $218-221$.

Impellizzeri, F. M., Marcora, S. M., Castagna, C., Reilly, T., \& Sassi, A., Iaia, F. M., \& Rampinini, E. (2006). Physiological and performance effects of generic versus specific aerobic training in soccer players. Generic versus Specific Aerobic Training in Soccer Players. International Journal of Sports Medicine, 27, 488 - 492.

Jack R. Frankel., Norman E. Wellen., H. H. Y. (2012). How to Design and Evaluate Research in Education. In M. Ryan (Ed.), How to Design and Evaluate Research in Education (8thed ed., pp. 1-642). New York:
McGraw-Hill.

Mackenzie, B. (2005). 101 Performance Evaluation Test. (B. Mackenzie, Ed.). London: Jonathan Pye.

Rampinini, E., Impellizzeri, F. M., Castagna, C., Abt, G., Chamari, K., Sassi, A., \&Marcora, S. M. (2007). Factors influencing physiological responses to small-sided soccer games. Journal of Sports Sciences, 25(6), 659-666. https://doi.org/10.1080/026404106008 11858

Ray, B. B. dan H. R. D. (2018). Perbandingan Metode Interval Training dan Continuous Run terhadap Peningkatan Vo2max. Jurnal Terapan Ilmu Keolahragaan, 1, 76-81.

Reilly, T., \& Ball, D. (1984). The net physiological cost of dribbling a soccer ball. Research Quarterly for Exercise and Sport, 55, 267 - 271.

Reilly, T., \& Gilbourne, D. (2003). Science and football: A review of applied research in the football codes. Journal of Sports Sciences, 21, 693 - 705.

Sugiyono. (2013). Metode Penelitian Pendidikan (18th ed.). Bandung: Alfabeta.

Tudor O. Bompa. (1983). Theory and methodology of training. Dubusque: Kendall/Hunt. 